\title{
A CRISE REPRESENTATIVA COMO CONCEITO LIMITE: NORMATIVIDADE SIMBÓLICA E O PROBLEMA DO DECISIONISMO EM CARL SCHMITT
}

Fernando Rodrigues de Almeida Oswaldo Giacóia Junior

SUMÁRIO: Introdução; 2. Normalidade e Exceção; 3. A Atividade Legiferante como Fórmula de Compromissos Dilatórios; 4. A Exceção como Via Principal da Democracia Liberal; 5. Considerações Finais; Referências.

RESUMO: O presente trabalho tem como objetivo analisar a relação entre exceção e normalidade, investigando a possibilidade da atividade legiferante em vias excepcionais em um sistema social vigente. Da mesma forma, as consequências de tais vias e a clássica crítica conservadora a liberalismo que não decide e age por vias de compromissos dilatórios. Finalmente observaremos a relação de significação da ordem jurídica para o representado que não se identifica com o sistema legislativo e seu reconhecimento aos signos legais. $O$ presente trabalho será realizado pelo método hipotético-dedutivo, utilizando-se de pesquisas bibliográficas.

PALAVRAS-CHAVE: Decisionismo; Democracia; Estado de Exceção.

\section{REPRESENTATIVE CRISIS AS A BORDER CONCEPT: SYMBOLIC NORMATIVITY AND THE DECISION ISSUE IN CARL SCHMITT}

ABSTRACT: The relationship between normality and exception is analyzed and the essay investigates the possibility of law-carrying activities by exceptional ways in current social system. Similarly, the consequences of these ways and the conservative classical critique against liberalism which does not decide nor acts through dilatory commitments are discussed. The author investigates the relationship of juridical order for the represented person who fails to identify himself with the legislation system and his acknowledgements of legal signs. Current analysis employs the hypothetic-deductive method through bibliographical research.

KEY WORDS: Decisionism; Democracy; State of Exception.

\footnotetext{
Mestrando em Teoria do Estado e do Direito pelo Centro Universitário Eurípides de Marília (UNIVEM); Bolsista CAPES/PROSUP; Secretário do grupo de pesquisa Rede Internacional de Estudos Schmittianos (RIES/ UNIVEM); E-mail: fernandordealmeida@gmail.com

${ }^{* *}$ Doutor em Filosofia pela Universidade Livre de Berlim; Docente Titular do Departamento de Filosofia, do Instituto de Filosofia e Ciências Humanas, da Universidade Estadual de Campinas (UNICAMP); Docente Colaborador do Programa de Mestrado em Direito do Centro Universitário Eurípides de Marília (UNIVEM), Marília (SP), Brasil.
} 


\section{LA CRISIS REPRESENTATIVA COMO CONCEPTO LÍMITE: NORMATIVIDAD SIMBÓLICA Y EL PROBLEMA DEL DECISIONISMO EN CARL SCHMIDT}

RESUMEN: El presente trabajo objetiva analizar la relación entre excepción y normalidad, investigando la posibilidad de actividad legislativa en vías excepcionales en el sistema social vigente. De igual forma, las consecuencias de tales vías y la clásica crítica conservadora al liberalismo que no decide y actúa por vías de compromisos dilatorios. Finalmente, observaremos la relación de significación de orden jurídico para el representado que no se identifica con el sistema legislativo y su reconocimiento frente a los signos legales. El presente trabajo será realizado por el método hipotético deductivo, utilizándose de investigaciones bibliográficas.

PALABRAS-CLAVE: Decisionismo; Democracia; Estado de Excepción.

\section{INTRODUÇÃO}

A discussão entre normalidade e exceção vai muito além do caráter de guerra e suspensão de direitos consolidados, a via da exceção age simplesmente no momento em que uma finalidade soberana é gerida de forma insólita.

A democracia liberal traz em seu cerne um óbice ao desenvolvimento democrático, qual seja a fuga da representação direta, priorizando interesses políticos e estabilidade de instituições liberais.

A necessidade de entender sociologicamente um sistema social, para argumentar que o subsistema jurídico-político faz parte de um sistema social que garante a existência de um ordenamento em conjunto com os demais subsistemas, é de necessária importância para investigar-se o sentimento de superioridade das instituições do Estado, que construíram-se a partir da própria instituição Estado Democrático, com o único objetivo de guiar-se em função da democracia.

A utilização das vias de exceção dentro da normalidade, seja em caráter jurídico ou político, lança um alarde para a necessidade de observar os riscos da suspensão do valor e dignidade humana, natural em um estado de exceção.

A observação do caráter teórico da exceção e normalidade, os resultados da democracia liberal e os institutos agindo excepcionalmente de sua função, para finalmente entender o sentido da identificação e significação da normalidade para o sujeito de direito norteiam o presente estudo que se dividirá em três partes. 
Inicialmente será investigado, apoiando-se em Carl Schmitt e seu conceito de situações limite, um olhar teórico acerca de normalidade e exceção do ponto de vista de um Estado de Direito. A partir da noção de Estado de Exceção será possível a análise de um Estado de normalidade em um âmbito constitucional e, consequentemente, qual a influência de tais momentos constitucionais sobre o sujeito de direito sobre a égide de um Estado.

Logo após, será observado, ainda sobre o referencial de Carl Schmitt, porém agora sustentando-se na teoria dos sistemas de Niklas Luhmann, a atividade legiferante utilizando a suspensão e procrastinações de discussões como fórmula de redução de conflitos políticos e interesses econômicos. Para isso, observaremos a fragilidade democrática resultante de tal fórmula e as vias excepcionais adotadas para sustentar tais procedimentos.

Finalmente, dentro de um Estado de normalidade, serão observados elementos característicos da exceção instrumentalizados como métodos políticos no Estado Democrático, para que se legitimem interesses que serão relacionados com interesses da estabilidade de um sistema liberal. A manutenção de interesses políticos e atos excepcionais serão utilizados para demonstrar fórmulas de mascaramento de uma atividade limítrofe como modelo de sustentação democrática. A partir de Giorgio Agamben será possível observar a relação das vias políticas excepcionais e a suspensão de direitos básicos do sujeito de direito.

O presente estudo não visa esgotar as discussões no que concerne à temática do Estado de Exceção, porém de observar as situações limites adotadas pelo estado de normalidade e, principalmente, a interferência sobre sujeito exposto à vontade política, bem como a crise de identificação entre representante e representado.

A partir de um método hipotético-dedutivo, a pesquisa bibliográfica é o cerne da discussão, como fórmula de observação de um modelo constitucional e seus riscos de desvio de finalidade.

\section{NORMALIDADE E EXCEÇÃO}

O conceito de Estado de Exceção, como a decisão política de suspensão de direitos de determinado território, foi objeto de estudo de Carl Schmitt ${ }^{1}$ que,

\footnotetext{
1 SCHMITT, Carl. Teologia política. Tradução de Elisete Antoniuk. Belo Horizonte: Del Rey, 2006.
} 
no século XX, foi um dos principais teóricos a enfrentar uma nova teoria jurídicopolítica que funda-se no que pode ser classificado como pensamento de ordem, que, em outras palavras, une as teorias do decisionismo político e o institucionalismo como um modelo de um estado forte e regido por uma definição de soberania definida por situações limites.

Schmitt utiliza-se da Exceção para definir a normalidade de um Estado, para isso argumenta que um Estado concentra-se em ações de soberania que, por sua vez, é capaz de definir sua dimensão de poder por ações de decretação de exceção. Nesse sentido o autor em questão abre uma de suas principais obras predicando que "soberano é quem decide sobre o Estado de Exceção", de forma que a identidade do soberano é necessária para a manutenção de uma força interna do território.

\begin{abstract}
Schmitt sugere que já não é propriamente um soberano claramente identificado, reconhecido como tal por um critério de legitimidade qualquer, que tem a incumbência de estabelecer e garantir a ordem jurídica, decidindo também soberanamente, no decurso de uma tal legitimidade inicial, exceções às normas e às leis, mas que se passa exatamente o contrário; ou seja, que é agora o próprio exercício da decisão sobre a exceção que determina como tal quem é soberano ${ }^{3}$.
\end{abstract}

Isso significa dizer que a soberania não deve ser pensada pela sua legitimidade, uma vez que esse período foi vencido com o findar da Primeira Grande Guerra. A legitimidade da soberania já deve ser previamente determinada em seu nascimento, como em um nomos. Demarcado o território e a expansão do poder, o soberano já deve estar bem definido e ter sua legitimidade preestabelecida como um poder ocasional, que pode decidir sobre situações que envolvam sua própria existência. Ou seja, a soberania teria uma legitimidade originária, que percorreria seus limites em sua própria criação, para que sua decisão pudesse ocorrer se necessário fosse para manutenção do conceito de Estado.

Para o autor, pode-se observar que o modelo de governança deve ser dividido em: Estado, movimento e povo. Desta forma, o modo de governo soberano apresenta a formulação tipológica que contenha tais características nas formas de governo.

2 Ibid., p. 7.

3 SÁ, Alexandre Guilherme Barroso de Matos Franco. Decisionismo e ficção no pensamento de Carl Schmitt. Revista Brasileira de Estudos Políticos, n. 105, p. 21-46, 2012, p. 27. 
Hoje, não distinguiria já dois, mas três formas de pensamento científico-jurídico, a saber: além do normativista e do decisionista, o tipo institucional [...] Enquanto que o normativista puro pensa na regra impessoal e o decisionista realiza o direito justo da situação política corretamente conhecida mediante uma decisão pessoal, o pensamento jurídico institucional se expõe em ordenações e configurações suprapersonais. E enquanto que o normativista traz em sua corrução do direito o ato de um modo meramente funcional de uma burocracia estatal e o decisionista sempre em perigo de perder em um caráter pontual a estabilidade de todo grande movimento político, um pensamento institucional isolado conduz ao pluralismo de um processo estamental feudal carente de soberania. Assim, as três esferas de elementos da unidade política - Estado, movimento, povo - se podem ordenar nos três tipos de pensamento jurídico, tanto quanto ao fenômeno são como em sua forma degenerada. ${ }^{4}$

A exceção aqui traçada, do ponto de vista decisional, é tida como um casolimite (Ernstfall) da estrutura de poder concentrado no soberano. Para Schmitt o conceito de soberania possui um conceito vinculado a uma interpretação lógicojurídica, ou seja, a eminência da exceção englobaria justamente a decisão sobre um princípio jurídico prevista na normalidade.

Schmitt destaca que o problema da observação da limitação normativa não pode atender a eminência do caráter limítrofe social.

[...] quando Mohl (monographien, p. 626) diz que a avaliação sobre a presença de um estado de necessidade não poderia ser jurídica, parte ele do pressuposto de que uma decisão, em sentido jurídico, deve ser completamente deduzida do conteúdo de uma norma. No entanto, esta é a questão. Na generalidade, como Mohl constrói a frase, ela é somente uma expressão do liberalismo jurídico-estatal e desconhece o significado autônomo da decisãos.

Como é possível observar, o autor busca uma definição do conceito de decisão dentro da normalidade jurisdicional em risco, isto porque, para ele, a democracia liberal se afasta da subjetividade representativa, que seria seu escopo, sendo incapaz de manter a ordem, mais uma vez, em situações limítrofes, qual seja, o caso de extrema necessidade, sendo iminente o risco de existência do Estado.

Como uma crítica ao pensamento liberal, Schmitt aponta os compromissos dilatórios e o consequente refreamento de decisões como uma fórmula de 
manutenção da estabilidade de instituições ligadas ao Estado, ou seja, a "essência do liberalismo burguês não se decidir nessa luta, mas tentar, em vez disso, julgá-la

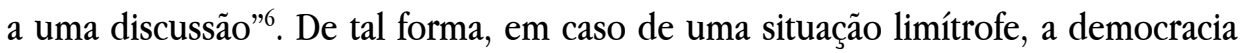
liberal seria incapaz de manter a ordem, vez que, em razão dos próprios interesses liberais, não seria possível a suspensão radical da normalidade, em detrimento de motins e manutenção da soberania.

O problema do liberalismo para Schmitt situa-se como uma contradição entre o próprio conceito de democracia. A procrastinação de compromissos apareceria como um resultado natural de tal sistema político, uma vez que a representatividade de interesses liberais, como segurança de garantias individuais, seria um óbice ao próprio conceito de representação.

[...] o olhar genealógico de Schmitt lança ao pensamento de Espinosa, assenta no facto de a contradição entre o liberalismo e a democracia [...] Por um lado, metafísica e filosoficamente, Espinosa apresenta-se a Schmitt como o primeiro adversário da idade clássica do racionalismo abstracto, instrumental e mecânico, da idade em que se iniciam essas movimentações profundas a que Schmitt chama "despolitizações e neutralizações", como o primeiro pensador a elaborar filosoficamente os conceitos de uma individualidade concreta e de uma potência inesgotável, próprias do fundamento da existência. ${ }^{7}$

A representação só seria possível se existisse uma legitimidade baseada na identidade com os representados, elemento que Schmitt nega existência na democracia liberal. Acima da representação existiria a necessidade de manutenção do status quo das instituições liberais, que por sua vez atingiriam diretamente a ação procrastinatória dos representantes políticos.

Em outras palavras, tal fenômeno significaria que a decisão a ser tomada pelo parlamento apenas existiria com o cuidado necessário para a garantia das instituições liberais, ou seja, em caso do rompimento da normalidade em relação à representação, não existiria decisão em razão do déficit representativo.

A própria característica materialista da democracia liberal, chave da crítica do pensamento conservador e, principalmente, do pensamento antropologicamente pessimista baseado em uma teologia política, guardaria o interesse econômico acima da soberania.

6 SCHMITT, Carl. A crise da democracia parlamentar. Trad. Inês Lobhauer. São Paulo: Scritta, 1996, p. 125. bocc.uff.br/pag/bento-antonio-carl-schmitt-teologia.pdf > . Acesso em: 04 ago. 2015, p. 4. 
Este quadro histórico e teórico evidencia o quanto Schmitt, leitor de Donoso, precisaria não apenas opor-se ao liberalismo como às estruturas políticas liberais, e estas encontram uma boa síntese em sua voraz oposição à cultura parlamentar e, com destaque, ao seu modo de operação, a pura tradução no mundo de que um esquema institucional caracterizado pela ineficiência. Estas são para Donoso, boas razões para que pudesse considerar o parlamentarismo e sua congênita inspiração liberal como absolutamente indesejáveis, pois todas estas características apontam para a implementação de um marco institucional político de alta instabilidade a partir de sua oposição ao decisionismo e aposta profunda na eterna discussão (e negociação). ${ }^{8}$

Nesse sentido, em sua obra "A crise na democracia parlamentar", o autor observa toda sua influência como leitor de Donoso Cortés, de forma que apresenta a crítica ferrenha ao modelo de democracia representativa liberal, que, em sua visão, deve ser combatida pela exceção, no momento em que é insustentável sua função representativa e, por conseguinte, coloca em risco o soberano.

Para ele, no contexto de situação limite, a ditadura é o oposto da discussão, ou seja, as negociações liberais de nada serviriam para a manutenção da ordem. A decisão seria o contexto claro de manutenção da normalidade.

A normalidade, portanto, é condição e escopo da exceção. Ou seja, para Schmitt, a própria exceção deriva da norma, ou seja, é necessária a existência da normalidade e, consequentemente, da ordem jurídica, para a limitação do poder soberano, que, por sua vez, se mantém por meio da exceção. Da mesma forma que a normalidade garante a existência da soberania, a exceção garante a existência do soberano, sem espaço para discussões que podem colocar em risco o Estado.

Dessa forma, a característica mater do liberalismo, qual seja, a estabilidade, não se mantém de forma estritamente materialista. Ou seja, de fato, os interesses econômicos necessitam de estabilidade, porém a condição soberana do Estado está acima dos interesses particulares.

Seria uma rudimentar transferência da disjunção esquemática socio-
lógica e doutrina jurídica, se quiséssemos dizer que a exceção não
teria significado jurídico e seria, por conseguinte, "sociologia". A
exceção não é subsumível; ela se exclui da concepção geral, mas,
ao mesmo tempo, revela um elemento formal jurídico específico,
a decisão na sua absoluta nitidez. Em sua configuração absoluta, o

8 BUENO, Roberto. Carl Schmitt e Donoso Cortés: entre autoritarismo e ditadura. Novas edições acadêmicas. Saarbrücken, Deutschland: Verlag. 2013a, p. 126.

9 SCHMITT, Carl, 1996, op. cit. 
estado de exceção surge, então, somente quando a situação deva ser criada e quando tem validade nos princípios jurídicos. Toda norma geral exige uma configuração normal das condições de vida nas quais ela deve encontrar aplicação segundo os pressupostos legais, e os quais ela submete à sua regulação normativa. ${ }^{10}$

Observa-se, portanto, que para Schmitt, a própria exceção trata de um ato decisional jurídico. A existência da decisão só garante que o próprio ordenamento se mantenha. Na lógica schmittiana, a norma necessita de um meio homogêneo, ou seja, "essa normalidade fática não é somente um 'mero pressuposto' que o jurista pode ignorar. Ao contrário, pertence à sua validade imanente"11.

Isso significa que a própria existência da norma só faz sentido se sua finalidade é normal, ou seja, a atividade normativa necessita da normalidade. Nesse sentido Schmitt entende como ordem a expressão que dá sentido à norma.

De modo que, a normalidade em crise, em uma situação limítrofe de exercício de Estado, a norma não alcança mais sua finalidade. Em crise, ou melhor, no limite, a norma perde sua efetividade.

A legalidade perante a efetividade é corolário da exceção. A pura legalidade não define, no conceito schmittiano, a via da normalidade. Uma norma sem sentido faz do soberano algo que não condiz com o conceito romântico do poder que nada responde.

Para Schmitt, a legalidade por si não bastaria para definir a estabilidade do Estado de Direito, necessitando, portanto, do ato normativo que suspende a própria existência da legalidade, uma vez que tal legalidade não se justifica mais por si. Tal posição se contrapõe sensivelmente ao pensamento kelseniano que, por sua vez, definiria a legitimação da soberania a partir de uma omissão internacional quanto a sanções derivadas de obrigações recíprocas entre Estados, definindo o Direito Internacional. O que significaria que a existência do Soberano depende da existência de uma ordem normativa e da possibilidade de coexistência entre Estados de Direito.

Segundo a determinação do conceito de Direito que aqui propusemos, o chamado Direito internacional é Direito se é uma ordem coercitiva da conduta humana, pressuposta como soberana; se luga aos fatos por ele definidos como pressupostos atos de coerção por ele determinados como consequências e, portanto, pode ser descrito

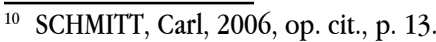

${ }^{11}$ Idem. 
em proposições jurídicas, da mesma forma que o Direito estadual ${ }^{12}$ (KELSEN, 1998, p. 355).

Para Schmitt a soberania não deve depender da vontade de um Direito Internacional para legitimar sua existência, pelo contrário, a força do Estado deve guiar-se pela sua soberania, por conseguinte, pela defesa de seu território sobre qualquer interferência externa, que seria caracterizada como força inimiga.

A exceção nada mais faz do que decidir o ponto de resgate de um Estado em crise, ou seja, nesse diapasão a exceção não suspende a normalidade, uma vez que a ordem jurídica já não existia por não se justificar em si mesma. A exceção apenas buscaria o resgate da normalidade, sem necessidade de justificação de interesses, que aos poucos enfraqueceriam a soberania.

A crítica de Schmitt se concentra, portanto, em um sistema parlamentar que havia se transformado em uma mera fachada daqueles propósitos que o liberalismo, por excelência, defendia, a saber, que todo processo de surgimento da averiguação dos anseios políticos populares poderiam ser averiguados em sua seara. ${ }^{13}$

Como se observa, Schmitt defende uma democracia procedimental, ao contrário do modelo pluralista e procedimentalista da democracia liberal, isto porque o sentimento de representação deveria, aos óculos do autor, ser necessariamente o ponto de justificação da normalidade, em razão da normatividade, de forma que a característica de dilação de compromissos do parlamento colocava um óbice na própria realização da normalidade.

O modelo da decisão da exceção, para o autor, no caso, provaria a própria existência da normalidade; nesse sentido, o modelo excepcional apenas justificaria a existência daquilo que a normalidade busca. Ou seja, em crise, a normalidade tornase sem sentido, o sentido, por sua vez é resgatado pela própria exceção, que só pode ser tomada em razão da decisão soberana na suspensão da normalidade, que recuperaria (ou reformaria) a normalidade, no caso, a ordem jurídica que justificaria sua realidade, ou melhor, representaria aqueles para quem a norma é direcionada.

A exceção é mais interessante do que o caso normal. O que é normal

${ }^{12}$ KELSEN, Hans. Teoria pura do direito. Tradução João Baptista Machado. 6. ed. São Paulo: Martins Fontes, 1998 , p. 355.

${ }^{13}$ BUENO, Roberto. Las vías modernas del conservadorismo autoritario: de Donoso Cortés a Carl Schmitt. Saarbrücken/Deutschland: Verlag. 2013b, p. 48 - Tradução livre do autor. In verbis: La crítica de Schmitt se centra, por tanto, en que el sistema parlamentar se había transformado en una mera fachada de aquellos propósitos que el liberalismo, por excelencia, defendia, a saber, que todo el processo de surgimento de la averiguación de las ansias políticas populares pudiesen ser averiguadas en esta órbita. 
nada prova, a exceção comprova tudo; ela não somente confirma a regra, mas esta vive da exceção. Na exceção, a força da vida real transpõe a crosta mecânica fixada na repetição. Um teólogo protestante, no século XIX, provou de que a intensidade vital a reflexão teológica pode ser capaz: "a exceção explica o geral e a si mesma". E, quando se quer estudar corretamente o caso geral, somente se precisa observar uma real exceção. Ela esclarece tudo de forma muito mais clara que o geral em si. Com o tempo, fica-se farto do eterno discurso sobre o geral; há exceções. Não se podendo explicá-las também não se podendo explicar o geral. Comumente, não se nora a dificuldade por não se pensar no geral com paixão, porém com uma superficialidade cômoda. A exceção, ao contrário, pensa o geral com paixão enérgica. ${ }^{14}$

Há sempre um risco na adoção das teorias de Carl Schmitt como fundamento teórico devido suas posições favoráveis à ditadura, porém, com todo o cuidado necessário, podemos interpretá-lo como fórmula de sustentação do momento em que a normalidade mais nada representa senão apenas interesses políticos setorizados e discussões que evitam decisões para o contento de uma normalidade materialista, a exceção reafirma o que a representação justificaria da normalidade.

Para o autor, a fundamentação da normalidade repousa na efetividade da legalidade, que vence ao longo do tempo, que entra em crise, que desaba em seus signos legais. Porém, preocupa-se o autor, com o modelo democrático liberal, que mantém a normalidade, ainda que ela não se justifica em si mesma, tornando-se apenas um reflexo de interesses partidários em busca do corolário materialista da forma jurídica.

No caso, Schmitt apresenta um modelo de criação de normalidade a partir da decisão, ou seja, o próprio soberano decide sobre o início da soberania, a partir de que este, nas próprias palavras de $S$ chmitt ${ }^{15}$, "O soberano permanece fora da ordem legal normal e, todavia, pertence a ela”.

Isso significa que, para Schmitt, há um modelo de decisionismo institucional, ou seja, o soberano é parte da ordem jurídica, uma vez que ele decidiu sobre seu começo e pode determinar seu fim, do ponto de vista da normalidade, porém, dentro da normalidade, as instituições presentes, criadas ex nibilo (bem como qualquer decisão), regem os modelos de valor presentes em um Estado de normalidade.

Para Schmitt, a decisão soberana nasce de uma decisão necessaria-

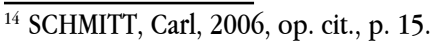

${ }^{15}$ Ibid., p. 39. 
mente arbitrária que instaura uma ordem na qual atuam as instituições. A decisão soberana instaura uma normalidade em substituição ao caos. O "concretismo" de Schmitt combina instituição à decisão de maneira sincrética, coerente e sistemática. As instituições nascem de uma decisão arbitrária, mas ganham autonomia, formando-se uma "vontade institucional". As instituições, na medida em que são sedes de autoridades, criam valores e conteúdos, os quais, por sua vez, influenciarão na própria formação do poder soberano que decide, em última instância, sobre qual é a normalidade que será posta em substituição ao caos. Por fim, o Estado, enquanto "Instituição das Instituições", une e subordina as demais instituições, estabelecendo uma relação de hierarquia entre elas. O decisionismo institucionalista schmittiano consiste nesse sistema de imbricação e dependência, que combina o elemento ocasional da decisão originária (da soberania ou da instituição) com a dinâmica de criação de valores e conteúdos do jogo institucional. ${ }^{16}$

Nesse contexto, a conclusão leva a um modelo decisionista institucional de Schmitt, a normalidade é definida pela justificativa sociológica das próprias instituições presentes no Estado, que decidem dentro do modelo jurídico normal. Porém, no momento que o ordenamento não se justifica mais em meio à decisão sociologicamente presente, uma vez que com a normalidade em crise necessita-se da interferência decisional do soberano, que é parte da ordem jurídica, porém se mantém fora dela.

Para Schmitt, a normalidade só se justifica na representação, logo em situações limítrofes não há mais normalidade; dessa forma, pouco importariam as discussões parlamentares, a ordem soberana já estaria em risco e sem fundamento de existência, a não ser pela legalidade pura, nesse contexto que o soberano interferiria por meio da exceção.

\section{A ATIVIDADE LEGIFERANTE COMO FÓRMULA DE COMPROMISSOS DILA- TÓRIOS}

Ao perceber as características de uma estrutura schmittiana sobre a decisão, resta observar o modelo democrático vigente, de forma juridicamente sociológica, com a finalidade de entender a estrutura da normalidade da ordem jurídica existente.

Para isso, nesse ponto, a ordem jurídica como parte de um sistema social,

\footnotetext{
${ }^{16}$ MACEDO JUNIOR, Ronaldo Porto. O decisionismo jurídico de Carl Schmitt. Revista Lua Nova, n. 32. Disponível em: <http://www.scielo.br/scielo.php?pid=S0102-64451994000100011\&script=sci_arttext\#nt48> Acesso em: <18 dez. 2014> 1994.
} 
aos moldes de Niklas Luhmann ${ }^{17}$, para uma justificativa mais ampla do modelo democrático que expõe a representatividade a uma crise democrática, uma vez que o decisionismo sociológico permanece patente no trabalho de Luhmann.

Em um apanhado da teoria sistêmica, é possível categorizar o sistema social como um corpo observado do ponto de vista da redução de complexidade de seus entes sociais.

Como parte da atividade de relações interpessoais, os membros do sistema social procuram reduzir a complexidade de sua existência em sociedade por meio de suas funções exercidas nesse meio. De forma materialista, os indivíduos se agrupam em métodos de conhecimento e capacidade prática, ou seja, de acordo com sua atuação específica de funcionamento sistemático - do ponto de vista capitalista - do meio.

De forma natural, o significado dos entes passa a ser definido pela redução de sua complexidade por meio de sua funcionalidade, nesse ponto o sistema social passa a se dividir em grupos sociais, categorizados por Luhmann como subsistemas sociais.

Para o autor, cada subsistema reduz sua complexidade de acordo com sua função; dessa forma, os subsistemas passam a ser identificados de maneira generalizada, como o subsistema jurídico-político, subsistema médico, subsistema artístico, e assim por diante.

A intercomunicação desses grupos é perene, afinal os subsistemas são apenas a redução da complexidade do sistema social, entretanto, por motivos expressos dessa diminuição, cada subsistema se comunica apenas em razão de seu significado social, ou seja, cada grupo observa os outros a partir de seus conhecimentos funcionais do sistema social.

Insta argumentar que Luhmann vê o direito como um subsistema social, como todos os outros sistemas criados por um gesto de diferenciação das funções exercidas de forma materialista dos sujeitos envolvidos em uma sociedade, sem abrangência sobre os outros, mas sim interdependentes e em constante comunicação.

A sociedade não pode ser reconstruída apenas a partir de sua constituição jurídica. O direito é apenas um momento estrutural entre outros. Por isso uma compreensão adequada do caráter social do direito não pode ser alcançada apenas pela exegese e pela interpretação, e também não se esgota na busca de sua imposição. Mais que

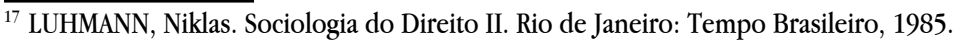


isso, a sociologia do direito deve começar indagando quanto à compatibilidade estrutural do direito ${ }^{18}$.

Na teoria de Luhmann, a aplicação dos sistemas sociais é feita de forma indireta, de modo que é necessário desatrelar a realidade objetiva da interação social cotidiana para elucidar o entendimento de seu funcionamento. Assim sendo, o estudo da realidade de um meio social, para Luhmann, significa, em um primeiro momento, observar as características e funções que eclodem do sistema social, para que por derradeiro, apliquem-se os resultados obtidos à realidade fática. Nesse sentido pontifica o instituidor da teoria em comento:

A sociedade é aquele sistema social cuja estrutura regula as últimas reduções básicas, às quais os outros sistemas sociais podem referirse. Ela transforma o indeterminado em determinado, ou pelo menos em uma complexidade determinável para outros sistemas. A sociedade garante aos outros sistemas um ambiente por assim dizer domesticado, de menor complexidade, um ambiente no qual já está excluída a aleatoriedade das possibilidades fazendo assim com que ele apresente menos exigências à estrutura do sistema ${ }^{19}$.

Como dito, a redução de complexidade é apresentada em um "sistema de diferenciação". A forma materialista da relação de funções deriva da estrutura adotada para significação do ente social sobre o modelo social. Dessa forma, a sociedade tem significado não pela condição humana de seu ente, porém no significado social que este ente apresenta.

Nesse sentido, o problema decisional do subsistema jurídico-político, sua função sistemática, que o dá significado, integrando seus entes em um gesto de diferenciação e identificação social.

Tal subsistema é observado na sociologia luhmanniana de forma aberta em termos cognitivos. Isso significa que sua função é reguladora e de manutenção da ordem jurídica que legitima a existência internacional do sistema social, em termos políticos. Dessa forma, o susbsistema jurídico-político toma para si a necessidade de observar os outros subsistemas não necessariamente somente de acordo com suas cognições de significado, mas em uma função sensível de percepção dos outros subsistemas.

\footnotetext{
18 Idem, p. 121.

${ }^{19}$ TRINDADE, André Fernando dos Reis. Para entender Luhmann e o Direito como sistema autopoiético. Porto Alegre: Livraria do Advogado, 2008, p. 26-27.
} 
O subsistema jurídico-político tem a necessidade de apresentar-se acolhedor e aberto ao entendimento das demandas dos outros subsistemas que a ele recorrem por sua finalidade de organização social e, por conseguinte, estar atento à comunicação intrasistêmica de modo circunspecto. Em outras palavras, o sistema jurídico é, insolitamente, preceptor de todos os outros subsistemas.

A interdinamicidade dos subsistemas gera a observação da política e justiça como um subsistema superior e a própria definição de soberania, uma vez que será este que regerá a ordem. Esse fenômeno deriva da própria estrutura materialista, os interesses advindos desse regime são estruturalmente liberalistas, por conseguinte $o$ modo de atuação do direito e da política são garantidores da significação capitalista.

Logo, o subsistema jurídico-político apresenta um primeiro aspecto de sentimento de superioridade por parte dos outros subsistemas. Agrava-se o problema da diferenciação no momento que a justiça e a política têm um caráter fechado em termos operativos. Em termos de intercomunicatividade, não há diferença em sua abertura de significado. A complexidade da justiça, em termos políticos ou jurídicos, tem sua significação interna, que não é compreendida pelos outros subsistemas, senão do ponto de vista de significação natural de cada subsistema.

Observa-se que há uma dicotomia sistêmica, todo sistema só se entende a partir de si mesmo, se comunicando sempre, mas compreendendo apenas em suas participações sociais, da mesma forma, todos são fechados em suas estruturas, porém a justiça consegue observar os demais subsistemas em sua integralidade, por conta de sua necessidade ordenamental, porém não se abre cognitivamente aos outros subsistemas, gerando, portanto, um caráter de decisionista de atos, uma vez que se integra ao sentimento de próprio soberano.

Luhmann esclarece que a organização do indivíduo não se abaliza ao direito, mas sim em um rol incomensurável de possibilidades que estão enleadas às contingências intrínsecas da vivência humana. Nesse sentido, o sentimento de superioridade não passa de um símbolo.

Quem pode ter expectativas sobre as expectativas dos outros pode ter um acesso mais rico em possibilidades ao seu mundo circundante, e apesar disso viver mais livre de desapontamentos. Ele pode superar a complexidade e as contingências mais elevadas, em um nível mais abstrato. Ele pode, se não for demasiadamente atrapalhado por motivos próprios, realizar internamente as adequações comportamentais necessárias, ou seja, quase sem comunicação. Ele não precisa expor-se e fixar-se verbalmente e ele economiza tempo, conseguindo, portanto, conviver com outros em sistemas sociais 
muito mais complexos e abertos em termos de comportamento. Ele é capaz de reservar os processos de comunicação, morosos e delicados, para poucos pontos importantes de conflito, e escolher sobre o que se falarán ${ }^{20}$.

O fechamento funcional - resultante da sensação de superioridade funcional perante aos outros subsistemas, demonstrada como ilusória - possibilita uma autonomia que resulta em abertura para criação de funções além de sua finalidade precípua.

O procedimento jurídico é um mecanismo que possibilita a diferenciação e a autonomização funcional do sistema, afinal, se a ideia funcional não passa pelo procedimento legiferante, não será mais que propedêutica ideológica. A força do subsistema jurídico é abstrata, baseada em coerção, que faz do direito uma programação condicional, isto é, assim como em um programa de computador, os problemas apresentados à observância do direito somente podem ser analisados a partir de suas decisões.

Retornando a Habermas, o Direito contemporâneo é completamente adequado para a resolução de conflitos de integração social em sociedades pósconvencionais, o que prova sua competência comunicativa na ação ${ }^{21}$.

Como outrora apresentado por Kelsen ${ }^{22}$ o Direito é visto pela tipologia "ser/ dever ser", o que pode resultar sanção. Contudo, hodiernamente percebemos que o caráter sancionador da norma não é mais condição sine qua non para sua existência, o que demonstra que a força abstrata do direito está além de sua característica de programação condicional.

Causalidade e Imputação, como já observado, são dois diferentes modos de um nexo funcional, dois diferentes modos, nos quais duas questões de fato são ligadas uma com a outra como condição e consequência. A diferença entre ambos subsiste na circunstância de que a imputação (isto significa a relação entre uma conduta determinada como condição e a sanção como consequência descrita numa lei moral ou jurídica) é produzida por um ato de vontade, cujo sentido é uma norma, enquanto a causalidade (isto significa a relação entre causa e efeito descrita numa lei) é independente de toda e qualquer intervenção. ${ }^{23}$

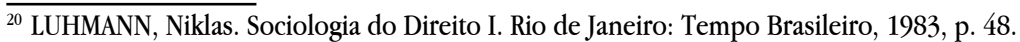

${ }^{21}$ POKER, Geraldo A. B.; MARTINS, Clélia Aparecida (Org.). O Pensamento de Habermas em questão. Marília: Oficina Universitária Unesp, 2008, p. 16.

${ }^{22}$ KELSEN, Hans. Teoria Geral das Normas. Trad. de José Florentino Duarte. Porto Alegre: Sérgio Antônio Fabris, 1986.

${ }^{23}$ Idem, p. 32.
} 
Se existe tanta independência funcional em um subsistema não é penoso imaginar sua autonomia em se desenvolver em desconformidade com os outros subsistemas, já que sua força abstrata é suficiente para justificar seus atos.

Quando um subsistema se considera menos necessitado de interdependência é uma questão de tempo de que apareçam ferramentas próprias criadas sem o englobamento das funções divididas em todo o sistema.

Finalmente encontramos nosso escopo. Com sua independência funcional o sistema político-jurídico criou ferramentas que fogem de sua finalidade basilar e a utilização de uma norma sem intenção de eficácia e efetividade é o exemplo claro da tergiversação de sua funcionalidade no sistema social.

O problema de que a própria falta de decisão que garante os interesses liberais do sistema social deriva da possibilidade de decisão sobre a omissão.

A significação do subsistema jurídico-político torna-se livre do ponto de vista de um único subsistema, o que dá origem à sua autopoiése sistêmica. A decisão pela omissão é legitimada por sua capacidade de autorregulação, o que foge do modelo ordenamental que o próprio subsistema garantiria.

A atividade legiferante como fórmula de compromisso dilatório ${ }^{24}$ tem como característica o processo legislativo democrático, que tem como predicado a divergência entre partidos políticos, o que se torna natural, mas, além disso, é intrínseco ao modelo político que vivemos.

A divergência entre partidos políticos em relação a determinado ato legislativo não chega a um consenso. Nessa situação, para evitar conflitos maiores, o ato normativo é aprovado, sem intenção de eficácia real, e procrastina-se a discussão do resultado mais favorável para os interesses partidários.

Nesta possibilidade a legislação serve como forma de compromisso dilatório, ou seja, transfere-se a responsabilidade da discussão do melhor texto para o ato normativo de um futuro incerto, e simboliza-se com a aprovação da norma, uma lei ineficaz, mas que não ofende o interesse de nenhum partido. Deixa-se porvir a solução do conflito em relação à necessidade social.

\footnotetext{
${ }^{24}$ SCHMITT, Carl, op. cit, 2006. Os compromissos dilatórios (dilatorischen Formelkompromiss), ou não autênticos, estiveram muito presentes na segunda parte da constituição de Weimar, que tinha em seu texto obscuridades sem decisão, marcadas pelo caráter compromissório em razão da característica da democracia liberal de evitar conflitos partidários. Dessa forma a assembleia se furtaria da decisão em razão das intenções dos partidos de coalizão. Como exemplo Schmitt cita a relação entre Igreja e Estado, que em conflito aos interesses do partido católico e do partido socialista, a assembleia não definiu a legalidade ou não do repasse do Estado à Igreja, o que para Schmitt se trata de manutenção do conflito sobrestado, o que ainda sim seria uma decisão em favor da unidade política.
} 
A preocupação de Schmitt toca o ponto em que as dificuldades de decisão sobre matérias relacionadas à constituição coloquem em risco a própria existência da soberania. Da mesma forma, a normalidade não existiria a partir de procrastinação decisória sobre matérias de urgência discussão, do ponto de vista democrático.

\begin{abstract}
Mas o interesse prático em uma decisão a respeito da colisão de leis não se dirige, em geral, a tais casos de uma contradição manifesta que, em tempos normais, não serão muito frequentes, nem a uma posterior correção de infrações perpetradas no passado, mas à pergunta de tipo bem diferente acerca de quem decide dúvidas e diversidades de opinião a respeito se existe ou não uma contradição e até que ponto ela existe. Tendo em vista a Constituição de Weimar, o interesse nessa questão é muito grande, pois especialmente na segunda parte estão colocados, lado a lado, os mais variados princípios, disposições particulares de direito material, programas e diretrizes, assim como compromissos dilatórios incertos, se se qualificarmos como "normas" todos esses diferentes preceitos, a palavra norma terá perdido seu valor e se tornado inútil. ${ }^{25}$
\end{abstract}

Por conseguinte, a harmonia social derivada da redução de complexidade só é eficaz a partir dos subsistemas organizados pelo subsistema jurídico-político. Por sua vez, o âmbito político-jurídico não realiza suas funções do sistema social integralmente, ao contrário, o modifica por meio excepcional não representativo, tampouco organizacional, porém, realiza seus interesses específicos fora da harmonia do sistema social.

\title{
4 A EXCEÇÃO COMO VIA PRINCIPAL DA DEMOCRACIA LIBERAL
}

A normalidade do ordenamento se deve à sua finalidade. A função sistemática do ordenamento apresenta relações diretas com toda a estrutura social que se configura em um contexto social e político.

A norma que atua fora dos padrões de sua finalidade pode alcançar um patamar de ausência de significado. Como percebe-se na crítica schmittiana leitor de Donoso Cortés ${ }^{26}$ - a exceção apresenta-se como via de situações-limite da normalidade.

\footnotetext{
${ }^{25}$ SCHMITT. Carl. O guardião da Constituição. Tradução de Geraldo de Carvalho. Belo Horizonte: Del Rey, 2007, p. 65.

${ }^{26}$ Ver SCHMITT, Carl. Donoso Cortes in gesamteuropäischer Interpretation: Vier Aufsätze. Köln: Greven, 1950.
} 
A atuação política na via liberal, como na crítica apresentada, acompanha um caráter de significação puramente político, ou seja, a representação não é a via principal da atividade legiferante, porém é a harmonia de interesses políticos que definem as negociatas e concessões parlamentares, nesse sentido, sendo muito comum o uso de compromissos dilatórios.

Mais uma vez, a norma não exprime a representação, de forma que aqueles submetidos a ela não têm a possibilidade de identificação com o legislador, tampouco o significado intrasistêmico do conteúdo dos signos presentes no texto.

Vale aqui destacar o pensamento de Giorgio Agamben sobre o conceito de bando, que define justamente a partir do texto kafkiano "Diante da lei", a relação do significado irrelevante da lei para aquele que é atingido por ela. A lei e a ordem têm uma relação que não necessariamente gere significado recíproco, ou seja, para Agamben, na interpretação de Kafka, a atividade legiferante de interesses específicos e não necessariamente representativa cria um fenômeno de bando, que em razão de uma tradição, de fato ideológica, não representa, ou melhor, não dá significado àquele sujeito de direito que recebe sua força normativa.

Vigência sem significado (Geltung obne Bdeutung): nada melhor do que esta fórmula, com a qual Scholem caracteriza o estado da lei no romance de Kafka, define o bando do qual o nosso tempo não consegue encontrar saída. Qual é, de fato, a estrutura do bando soberano, senão aquela de uma lei que vigora, mas não significa? Por toda parte sobre a terra os homens vivem hoje sob o bando de uma lei e de uma tradição que a mantém unicamente como ponto zero do seu conteúdo, incluindo-os em uma pura relação de abandono. Todas as sociedades e todas as culturas (não importa se democráticas ou totalitárias, conservadoras ou progressistas) entraram hoje em uma crise de legitimidade, em que a lei vigora como pura nada da Revelação. Mas esta é justamente a estrutura original da relação soberana, e o niilismo em que vivemos não é nada mais, nesta perspectiva, do que o emergir à luz desta relação como tal ${ }^{27}$.

As relações de legitimidade e legalidade e, também, da legitimidade da forma jurídica, têm para o filósofo italiano, diante do tradicionalismo, uma relação da lei em sua forma original, sem significação para aqueles sob sua égide, o que gera uma perene relação de validade com sua legitimidade apenas vigente na própria lei e não no caráter representativo, o que é gerada por uma "vontade pura, isto é, determinada somente mediante uma tal forma de lei, não é 'nem livre, nem não livre'" 28 .

\footnotetext{
${ }^{27}$ AGAMBEN, Giorgio. Homo Sacer: o poder soberano e a vida nua I. Tradução de Henrique Burigo. Belo Horizonte: UFMG, 2007, p. 58.

${ }^{28}$ Ibid, p. 59.
} 
A relação da identificação com a lei é forma essencial do seu significado, o modelo da democracia liberal, que leva em consideração precipuamente os interesses políticos e de estabilidade da moeda que fazem da relação democrática um símbolo sem finalidade e significação para aqueles que estão sob a vigência da legislação.

Os institutos liberais, sob a perspectiva de Carl Schmitt, como um instrumento de representatividade democrática com o intuito de evitar discussões em nome da representatividade, têm o dever de manutenção do sistema econômico e o desenvolvimento de redução de riscos do tratado social em virtude da axiologia do capital e dos interesses partidários, os ideais e cultura burguesa são mantidos pelo lobby dos institutos liberais, dentre eles o próprio poder legislativo, que necessita da manutenção da produção de verdade capitalista, conforme se observa:

A teoria de esquerda é anti-liberal. Mas a mais convincente e coerente crítica das instituições liberais neste século foi desenvolvida por Schmitt. Como muitos alemães que se posicionaram contra o liberalismo, a crítica de Schmitt foi fundamentada na metafísica e na cultura. Em seus ensaios anteriores a primeira guerra mundial (Schattenrisse, 1913; Theodor Däubler's "Nordlicht", 1916, "Die Buribudken", 1918) ele questionou valores e gostos burgueses e desafiou a crença liberal no progresso tecnológico. Political romanticism (1919) foi a ponte para seu trabalho que viria sobre política e lei. Sua crítica cultural se transformou em uma crítica da razão que identificou os objetivos do liberalismo alemão, o que Schmitt chamou de "romantismo político". A atitude burguesa foi satirizada em trabalhos iniciais que foram transformados através da figura de Adam Müller em "occasio"; Romanticismo foi "ocasionalmente subjetivado" quando Schmitt veio a analisar o parlamentarismo liberal, concluindo que a atividade central dos românticos - diálogo infinito (ewige Gesprache) - encontrou expressão no hábito liberal burguês de evitar decisões através de discussões. ${ }^{29}$

\footnotetext{
${ }^{29}$ KENNEDY, Ellen. In: LUKE, Tim; PICCONE, Paul; SIEGEL, Fred; TAVES, Michael (Org.). TELOS, n. $71-$ the crisis in higher education: intellectuals and the Academy. New York: Telos Press, 1987, p. 39. Tradução livre do autor. In verbis: Leftist theory is anti-liberal. But the most cogent and coherent critique of liberal institutions in this century was developed by Schmitt. Like much of German opposition to liberalism, Schmitt's critique was fundamentally metaphysical and cultural. In essays written before and during WWI (Schattenrisse, 1913; Theodor Däubler's "Nordlicht", 1916, "Die Buribudken", 1918) he questioned bourgeois values and tastes and challenged the liberal belief in progress and technology. Political Romanticism (1919) was a bridge to his later works on politics and law. His cultural criticism turned into a critique of reason that identified the goals of German liberalism with what Schmitt called "political romanticism". The bourgeois attitude he had satirized in earlier works was transformed through the figure of Adam Müller into "occasio"; Romanticism was "subjecfied occasionalism" when Schmitt came to analyses liberal parliamentarism he conclude that the Romantics central activity - "endless conversation" (ewige Gesprache) - found expression in the liberal bourgeoisie's habit of avoiding decision through discussion.
} 
Por esse viés, a democracia liberal tende a ser dependente do compromisso entre o falso e formal, ou seja, derivadas do interesse burguês, naturalmente tendentes a evitar o conflito por meio de discussões, a representatividade da democracia burguesa, justamente por sua característica de identidade com seus representados torna-se inseparável das instituições liberais.

O poder decisório fere a liberdade, por conseguinte, a constituição liberal tem por necessidade uma característica de iniciativa privada. A fórmula de dilação de compromissos para evitar as discussões é comum à iniciativa privada, pois, como foi trabalhado, para a manutenção dos baixos riscos do enfraquecimento da axiologia do capital é necessário lidar com mudanças que não distorçam a característica da moeda em um prazo proporcional à evolução da cultura.

O "compromisso de fórmula dilatório"30, conceito de Carl Schmitt apresentado em sua obra Verfassungslebre, utilizado para tratar da constituição de Weimar, mais tarde utilizado por Herald Kindermann ${ }^{31}$ para analisar a atividade legiferante hipertroficamente simbólica, trata justamente da necessidade do lobby legislativo no que tange a adiar as discussões sob a perspectiva de evitar conflitos dos interesses liberais-burgueses. Como bem traduzido pelo professor Marcelo Neves ${ }^{32}$ a legislação simbólica que adia a solução de conflitos sociais servirá como pilar

\footnotetext{
${ }_{30}$ Para Schmitt (1996b, p. 54-55): As determinações da Constituição de Weimar igualmente contêm uma série de compromissos não autênticos, caso contrário, para distinguir as decisões autênticas das questões de princípios, distinguiria também dos compromissos autênticos nas particularidades que não fossem sobre princípios, em que encontram sua regulação e ordenação objetiva, por meio de transações, detalhes de organização e de conteúdo. Poderiam ser chamados de compromissos apócrifos, porque não afetam as decisões objetivas, alcançadas por meio de transações, mas que precisamente, em sua essência, consiste em afastar e adiar a decisão. O compromisso baseia-se, então, em encontrar uma fórmula que satisfaça todas as demandas conflitantes e deixar indecisa, em uma expressão anfibológica, a questão controversa. Somente assim contém uma aproximação externa, verbal, para o conteúdo objetivamente inconciliável. Tais compromissos apócrifos são verdadeiros compromissos em certo sentido, pois não seriam possíveis se não houvesse acordo entre as partes. Porém, a inteligência não afeta a fundo; se apresenta apenas para adiar a decisão e deixá-la aberta para as mais distintas possibilidades e significados. O compromisso não afeta a solução objetiva de um problema por meio de transações objetivas, mas que o acordo tende a se contentar com uma fórmula dilatória que leva em conta todas as reivindicações. Também se encontram na Constituição de Weimar exemplos destes compromissos de fórmula dilatória. Esta destina-se a considerar somente as deliberações da Assembleia Nacional de Weimar. E. Vermeilha descreveu em sua obra sobre a Constituição de Weimar (Estrasburgo, 1923, sobretudo página 223) as contradições e a falta de uma "doutrina homogênea e coerente" no seio da Assembleia Nacional. Nos fortes contrastes eclesiásticos e sociais existentes na Alemanha e em uma situação tão crítica como foi a versão de 1919, não poderiam ser tratados compromissos dilatórios, se havia de se chegar a um resultado. Dado o pressuposto de que as decisões políticas essenciais foram adotadas, não havia razão que obstasse para atrasar a decisão de outras questões, deixando intacto, de pronto, os contrastes religiosos e sociais. Seria insensato e uma mostra de discernimento jurídico deficiente confundir e tomar por autêntico compromisso objetivo o compromisso de fórmula dilatória, persistentemente tratando contrastes objetivos de princípios com os métodos de tais fórmulas de compromisso dilatório - tradução livre do autor.

31 KINDERMANN, Harald. Symbolische Gesetzgebung. In: Jahrbuch für Rechtssoziologie und Rechtstheorie, 1988.

${ }^{32}$ NEVES, Marcelo. A Constitucionalização Simbólica. São Paulo: WMF Martins Fontes, 2007, p. 41.
} 
para corrigir "as divergências entre grupos políticos não resolvidos por meio do ato legislativo, que, porém, será aprovado consensualmente pelas partes envolvidas, exatamente porque está presente a perspectiva da ineficácia da respectiva lei”.

A ineficácia, nesse caso, se dá justamente pela impossibilidade de alterar o ordenamento em função dos interesses liberais, por conseguinte, para garantir a representatividade das classes dominantes (dominantes em relação ao capital que se funde à cultura) necessita de instrumentos jurídico-políticos que garantam a estabilidade e, consequentemente, a redução dos riscos.

A democracia liberal necessita de aparelhos ideológicos que mantenham os riscos baixos quanto ao valor capital, tudo isso em função de sua identidade representativa com a atividade burguesa, posto que é, de fato, adotada uma estrutura de seara privada, ou seja, com a adoção de adiamento de discussões, a fim de manter a estrutura ideológica cultural estável.

Para Nicos Poulantzas, o Estado constitui uma unidade política de classes dominantes, justamente por sua necessidade de representação de interesses, interesses esses ligados diretamente à necessidade de manutenção de cultura ideológica liberal burguesa:

Em relação principalmente às classes dominantes, em particular a burguesia, o Estado tem um papel principal de organização. Ele representa e organiza a ou as classes dominantes, em suma representa, organiza o interesse político a longo prazo do bloco no poder, composto de várias frações de classe burguesas (pois a burguesia é dividida em frações de classe), do qual participam em certas circunstâncias as classes dominantes provenientes de outros modos de produção, presentes na formação social capitalista: caso clássico, ainda hoje em dia, nos países dominados e dependentes, dos grandes proprietários de terra. Organização, na perspectiva do Estado, da unidade conflitual da aliança de poder e do equilíbrio instável dos compromissos entre seus componentes, o que se faz sob a hegemonia e direção, nesse bloco, de uma de suas classes ou frações, a classe ou fração hegemônica. ${ }^{33}$

O problema apresentado é justamente o fato de a democracia liberal agir em caráter limítrofe, ou seja, a finalidade da própria normatividade não se apresenta como garantidora da normalidade, sua legitimidade está ligada ao interesse político e não necessariamente à identificação dos sujeitos envolvidos.

$\mathrm{O}$ risco de tal crise democrática reflete em uma excepcionalidade como

\footnotetext{
33 POULANTZAS, Nicos. O Estado, o poder, o socialismo. São Paulo: Paz e Terra, 2000, p. 128-129.
} 
via de regra, ou seja, os argumentos contrarrevolucionários conservadores são estatuídos de forma a refletir os patamares atuais da democracia. Isso significa dizer que a democracia vivendo com institutos excepcionais trazem à baila um risco democrático de extremo perigo, como bem apontado por Roberto Bueno "reler o discurso do conservador e reacionário comprometido com o autoritarismo é de visceral importância sempre e quando temos em conta a proteção da cultura democrática e das instituições do Estado de Direito"34.

De fato, um bando soberano não representa uma democracia e, se englobado em um estado democrático, certamente são as vias da exceção exercendo a legalidade em prol dos interesses de um Estado que não representa e despista a normalidade.

\section{CONSIDERAÇÕES FINAIS}

A democracia ainda é o modelo de representação que dá ao povo o poder de autodeterminação. Em termos de autonomia a importância da organização social baseada no interesse do povo é o modelo mais próximo de um aufklärung kantiano em termos abrangentes.

A crise da democracia não nasce apenas do descontentamento com um governo, porém tem origens na própria formação do soberano, que em seu regime político deixa de representar e se autolegitima pela legalidade.

A crítica de Carl Schmitt às instituições liberais dentro de seu pensamento baseado da exceção e no autoritarismo apresentam uma atualidade assustadora que nos coloca a pensar nos riscos sociais que um modelo de democracia liberal em crise representa.

O objetivo certamente é o resgate da democracia, para isso observamos os aspectos de caráter limítrofe de um ordenamento e seu afastamento da normalidade, necessariamente em razão de um modelo representativo que atrasa discussões em razão de um interesse interno, o que faz do poder político um subsistema autopoiético.

Nesses termos, o resgate do conceito do bando soberano nos remete à

\footnotetext{
34 BUENO, Roberto, 2013b, Op. cit., p. 99. Tradução livre do autor. In verbis: Releer al discurso conservador y reaccionario comprometido con el autoritarismo es de visceral importancia siempre y cuando tenemos en cuenta la protección de la cultura democrática y las instituiciones del Estado de Derecho.
} 
falta de significação de um sistema democrático em crise que exerce o poder pela exceção, mas mantém a normalidade legalista, porém sem representação a aparente normalidade, já em crise, passa a gerar os conflitos de inocuidade no povo.

A simbologia legal é um conflito de padrões de estabilidade econômica e política, que deve ser combatido em favor de uma democracia que deve evoluir, de forma que, em um conflito puramente político e nada representativo estamos sempre fadados à estagnação ou, pior, aos motins e, consequentemente, uma exceção que deixa o ser em condições de precariedade ou a própria vida nua.

\section{REFERÊNCIAS}

AGAMBEN, Giorgio. Homo Sacer: o poder soberano e a vida nua I. Tradução Henrique Burigo. Belo Horizonte: UFMG, 2007.

BENTO, António. Teologia e mitologia política: um retrato de Carl Schmitt. Disponível em: <http://www.bocc.uff.br/pag/bento-antonio-carl-schmitt-teologia. pdf $>$. Acesso em: 03 mar. 2015.

BUENO, Roberto. Carl Schmitt e Donoso Cortés: entre autoritarismo e ditadura. Novas edições acadêmicas. Saarbrücken/Deutschland: Verlag, 2013a.

BUENO, Roberto. Las vías modernas del conservadorismo autoritario: de Donoso Cortés a Carl Schmitt. Saarbrücken/Deutschland: Verlag, 2013b.

GIACOIA JUNIOR, Oswaldo. Entre a regra e a exceção: fronteiras da racionalidade jurídica. In: Gramática dos direitos fundamentais. PADILHA, Norma Sueli; NAHAS, Thereza Christina; MACHADO, Edinilson Donisete (Org.). Rio de Janeiro: Campus jurídico, 2010.

KELSEN, Hans. Teoria pura do direito. Tradução João Baptista Machado. 6. ed. São Paulo: Martins Fontes, 1998.

KELSEN, Hans. Teoria Geral das Normas. Tradução José Florentino Duarte. Porto Alegre: Sérgio Antônio Fabris, 1986.

KINDERMANN, Harald. Symbolische Gesetzgebung. In: JAHRBUCH für Rechtssoziologie und Rechtstheorie, 1988. 
LUHMANN, Niklas. Sociologia do Direito I. Rio de Janeiro: Tempo Brasileiro, 1983.

LUHMANN, Niklas. Sociologia do Direito II. Rio de Janeiro: Tempo Brasileiro, 1985.

LUKE, Tim; PICCONE, Paul; SIEGEL, Fred; TAVES, Michael (Org.). TELOS, number 71: the crisis in higher education: intellectuals and the Academy. New York: Telos Press, 1987.

MACEDO JUNIOR, Ronaldo Porto. O decisionismo jurídico de Carl Schmitt. Revista Lua Nova, n. 32. Disponível em: <http://www.scielo.br/scielo.php?pid=S010264451994000100011\&script $=$ sci_arttext\#nt48> Acesso em: <18 dez. 2014> 1994.

NEVES, Marcelo. A Constitucionalização simbólica. São Paulo: WMF Martins Fontes, 2007.

POKER, Geraldo A. B.; MARTINS, Clélia Aparecida (Org.). O Pensamento de Habermas em questão. Marília: Oficina Universitária Unesp, 2008.

POULANTZAS, Nicos. O Estado, o poder, o socialismo. São Paulo: Paz e Terra, 2000.

SÁ, Alexandre Franco de. Decisionismo e ficção no pensamento de Carl Schmitt. Revista Brasileira de Estudos Políticos, Belo Horizonte, n. 10, p. 21-46, 2012.

SCHMITT, Carl. A crise da democracia parlamentar. Tradução Inês Lobhauer. São Paulo: Scritta, 1996.

SCHMITT, Carl. Teologia política. Tradução de Elisete Antoniuk. Belo Horizonte: Del Rey, 2006.

SCHMITT, Carl. Teoría de la Constitución. Versión española de Francisco Ayala. 2. ed. Madrid: Alianza, 1996b.

SCHMITT, Carl. O guardião da Constituição. Tradução Geraldo de Carvalho. Belo Horizonte: Del Rey, 2007.

SCHMITT, Carl. Donoso Cortes in gesamteuropäischer Interpretation: Vier Aufsätze. Köln: Greven, 1950. 
SCHMITT, Carl. Verfassungslehre. 8. ed. Berlin: Duncker \& Humblot, 1993.

TRINDADE, André Fernando dos Reis. Para entender Luhmann e o Direito como sistema autopoiético. Porto Alegre: Livraria do Advogado, 2008.

Recebido em: 19 de junbo de 2015 Aceito em: 05 de agosto de 2015 